\title{
Epidemiological status of suicide in the Middle East and North Africa countries (MENA) from 1990 to 2017
}

\author{
Saeed Amini ${ }^{\mathrm{a}}$, Parnia Bagheri ${ }^{\mathrm{b}}$, Mehdi Moradinazar ${ }^{\mathrm{b}}$, Mona Basiri $^{\mathrm{b}}$, Mostafa Alimehr ${ }^{\mathrm{c}}$, \\ Yousef Ramazani ${ }^{\mathrm{b}, *}$ \\ ${ }^{a}$ Department of Health Services Management, Health School, Arak University of Medical Sciences, Arak, Iran \\ ${ }^{\mathrm{b}}$ Behavioral Disease Research Center, Kermanshah University of Medical Sciences, Kermanshah, Iran \\ ${ }^{\mathrm{c}}$ Health Services Management, Dezful University of Medical Sciences, Dezful, Iran
}

\section{A R T I C L E I N F O}

\section{Keywords:}

Epidemiological status

Suicide

Middle east

North africa

\begin{abstract}
A B S T R A C T
Background: Suicide is proposed as an important and growing issue in public health. The aim of this study is to compare suicide load in the Middle East and North Africa (MENA) countries in order to pave the way for correct health policy making.

Methods: The population included 21 MENA countries. The data of Global Burden of Diseases in 2017 that estimate death rate for 264 causes was used. The GBD considers suicide according to definition of the ninth and tenth editions of the international classification of diseases as death due to poisoning or intentional self-injury. All suicide-related analyzes were evaluated using these indicators in excel 2016.

Results: The highest percentage of total suicide DALY attributable to risk factors of Alcohol and drug use are related to United Arab Emirates and Afghanistan countries, respectively. Iran is the sole country without suicide DALY attributable to alcohol consumption risk factor. Moroccan women and Libya, Afghanistan and Yemen men have the highest DALY rates in terms of ASR in the region, respectively. Suicide incidence have an increasing trend until the age group of 20-24 and then a decreasing trend. This trend is on the rise again since the age of 65 . Discussion: The necessity to improve social, cultural and economic factors along with effective measures on suicide prevention especially among low and middle income countries, performing more studies and precise registration of the cases especially in the areas that suicide is considered social stigma and crime should be considered as high agenda in national and regional strategies.
\end{abstract}

\section{Introduction}

Suicide is recognized as an important and growing public health concern in world health organization (WHO) and also as one of the components of comprehensive mental health program. ${ }^{1}$ The aim is to reduce suicide death toll by $10 \%$ between 2010 and 2020. Suicide has left more than 47,000 deaths in 2017 , in other words, one death per each $11 \mathrm{~min}^{2}$ The suicide rate has increased by $60 \%$ between 1960 and 2012 which approximately $75 \%$ of the cases have occurred in developing countries. ${ }^{3,4}$

Suicide rate is varying significantly between countries and over time. ${ }^{5}$ In 2016, 26,000 deaths in the Middle East and North Africa (MENA) were reported due to suicide that means 4.8 deaths per 100,000 deaths. $^{6}$ In the same year, suicide in the United States, with about 45,000 deaths, placed as the tenth main causes of death. Also, this rate has increased in the last few years so that it has obtained the highest rate in $2017 .^{7}$ China and India countries, with the highest number of absolute suicides, have more than half of all cases, partly due to high population of these areas. The lowest standardized age of death rate was reported in Lebanon, Syria, Palestine, Kuwait and Jamaica.

In 2012, death due to suicide in men was 1.8 times higher than women. ${ }^{5}$ This is while suicide attempt and self-harm in women are 2-4 times higher than men. ${ }^{8-10}$ In many countries, the highest rate of suicide has reported among middle-aged or elderly people. ${ }^{11,12}$ However, the absolute number of suicides among people aged 15 to 29 is seen due to the high population of this age group. ${ }^{5}$ Globally, the average age of suicide is between 30 and 49 years for men and women. ${ }^{13}$ Suicide is rare in children and increases during adulthood. In Southeast Asia, contrary to other parts of the world, suicide rates among young women are higher than older women. ${ }^{5}$ In developed countries, about $30 \%$ of young men's deaths are due to suicide. Suicide death rate in developed countries is similar with developing countries, but due to high mortality

\footnotetext{
* Corresponding author. Behavioral Disease Research Center, Kermanshah University of Medical Sciences, Kermanshah, Iran.

E-mail address: uoseframazani60@gmail.com (Y. Ramazani).
} 
Table 1

The comparison between suicide burden in the world and MENA countries in 1990 and 2017.

\begin{tabular}{|c|c|c|c|c|c|}
\hline Country & Year & Incidence rate of Self-harm by ASR & prevalence rate of Self-harm by ASR & death rate of Self-harm by ASR & DALYs rate of Self-harm by ASR \\
\hline \multirow[t]{2}{*}{ Afghanistan } & 1990 & $16.4(14.56-18.57)$ & $41.85(36.14-49.09)$ & $10.32(4.47-14.76)$ & $409.56(136.55-683.54)$ \\
\hline & 2017 & $15.78(13.51-18.26)$ & $40.53(34.81-47.84)$ & $9.19(7.42-12.54)$ & $363.1(277.19-582.32)$ \\
\hline \multirow[t]{2}{*}{ Algeria } & 1990 & $23.74(21.04-26.7)$ & $64.15(54.23-77.21)$ & $4.84(4.11-5.78)$ & $241.88(202.96-290.4)$ \\
\hline & 2017 & $21.51(18.12-25.33)$ & $54.36(45.95-65.65)$ & $4.12(3.41-4.87)$ & $199.41(163.48-238.5)$ \\
\hline \multirow[t]{2}{*}{ Bahrain } & 1990 & $30.04(26.66-33.95)$ & $77.48(64.84-91.92)$ & $5.68(4.95-7.12)$ & $250.78(220.35-305.87)$ \\
\hline & 2017 & $27.01(22.84-31.76)$ & $65.63(54.62-78.17)$ & $4.23(3.44-5.13)$ & $188.89(153.58-230.82)$ \\
\hline \multirow[t]{2}{*}{ Egypt } & 1990 & $17.91(15.74-20.27)$ & $49.02(41.77-59.01)$ & $5.04(3.96-6.18)$ & $241.38(190.72-296.93)$ \\
\hline & 2017 & $20.63(17.52-24.18)$ & $52.1(43.99-62.97)$ & $5.47(4.03-6.76)$ & $254.07(194.32-310.62)$ \\
\hline \multirow[t]{2}{*}{ Iran } & 1990 & $30.86(25.66-36.89)$ & $81.34(67.1-98.39)$ & $7.22(6.57-8.12)$ & $371.91(337.34-414.96)$ \\
\hline & 2017 & $28.16(22.25-35.47)$ & $69.48(57.36-84.51)$ & $5.45(4.79-5.8)$ & $272.5(236.93-290.01)$ \\
\hline \multirow[t]{2}{*}{ Iraq } & 1990 & $27.74(24.63-31.18)$ & $70.4(59.58-82.85)$ & $8.15(6.56-10.29)$ & $384.45(310.23-487.12)$ \\
\hline & 2017 & $17.71(15.18-20.56)$ & $46.58(39.73-55.85)$ & $4.09(3.66-4.7)$ & $191.17(170.27-228.21)$ \\
\hline \multirow[t]{2}{*}{ Jordan } & 1990 & $24.42(21.74-27.56)$ & $62.38(53.07-73.98)$ & $6(4.97-7.2)$ & $280.14(232.04-338.95)$ \\
\hline & 2017 & $19.66(16.42-23.29)$ & $48.38(40.61-58.14)$ & $3.22(2.73-3.73)$ & $145.34(122.67-168.54)$ \\
\hline \multirow[t]{2}{*}{ Kuwait } & 1990 & $21.59(18.89-24.73)$ & $54(45.64-64.55)$ & $2.79(2.55-3.02)$ & $138.21(125.77-152.11)$ \\
\hline & 2017 & $23.65(19.57-28.25)$ & $57.92(48.56-69.26)$ & $2.49(2.2-2.85)$ & $118.76(105.19-135.57)$ \\
\hline \multirow[t]{2}{*}{ Lebanon } & 1990 & $27.85(24.62-31.37)$ & $72.48(60.26-87.16)$ & $5.27(4.33-6.48)$ & $256.91(214.1-317.22)$ \\
\hline & 2017 & $27.27(23.06-31.71)$ & $65.93(54.75-79.9)$ & $4.78(3.8-5.65)$ & $232.92(187.12-277.2)$ \\
\hline \multirow[t]{2}{*}{ Libya } & 1990 & $28.99(26.01-32.46)$ & $74.38(62.75-88.83)$ & $6.45(5.08-7.97)$ & $307.33(243.18-383.61)$ \\
\hline & 2017 & $30.65(26.24-35.84)$ & $74.49(61.48-89.61)$ & $8.07(5.34-10.53)$ & $389.05(259.43-513.38)$ \\
\hline \multirow[t]{2}{*}{ Morocco } & 1990 & $27.23(24.24-30.43)$ & $70.53(59.63-84.27)$ & $8.02(6.93-9.53)$ & $387.13(333.08-461.9)$ \\
\hline & 2017 & $26.98(23.13-31.35)$ & $66.61(55.77-80.25)$ & $7.15(5.83-8.58)$ & $335.82(270.71-406.52)$ \\
\hline \multirow[t]{2}{*}{ Palestine } & 1990 & $19.81(17.27-22.69)$ & $51.92(44.09-61.82)$ & $5.34(3.85-6.83)$ & $261.99(184.88-339.13)$ \\
\hline & 2017 & $19.25(16.1-22.97)$ & $49.84(42.31-59.98)$ & $3.55(2.58-3.98)$ & $166.15(116.75-188.39)$ \\
\hline \multirow[t]{2}{*}{ Oman } & 1990 & $19.14(16.62-22.09)$ & $49.03(42.01-58.56)$ & $3.71(2.78-5.19)$ & $173.05(128.28-243.41)$ \\
\hline & 2017 & $18.91(15.73-22.49)$ & $45.67(38.52-55.47)$ & $2.92(2.27-3.77)$ & $131.92(102.21-171.52)$ \\
\hline \multirow[t]{2}{*}{ Qatar } & 1990 & $38.78(34.63-43.38)$ & $98.06(81.82-116.37)$ & $7.51(5.91-9.28)$ & $355.89(281.09-439.83)$ \\
\hline & 2017 & $31.09(26.09-36.43)$ & $78.43(64.85-95.14)$ & $4.64(3.51-5.95)$ & $221.05(160.19-288.52)$ \\
\hline \multirow[t]{2}{*}{ Saudi Arabia } & 1990 & $15.36(13.16-17.83)$ & $39.29(33.99-46.29)$ & $2.41(1.81-3.52)$ & $105.96(80.18-154.64)$ \\
\hline & 2017 & $22.05(18.25-26.3)$ & $52.1(44.01-62.43)$ & $2.95(2.22-3.78)$ & $129.01(94.7-169.61)$ \\
\hline \multirow[t]{2}{*}{ Sudan } & 1990 & $17.81(15.61-20.33)$ & $20.89(17.64-24.99)$ & $6.17(3.9-9.05)$ & $302.8(180.66-444.97)$ \\
\hline & 2017 & $16.91(14.49-19.71)$ & $20.03(17.02-24.17)$ & $5.02(3.91-6.38)$ & $239.26(184.95-302.99)$ \\
\hline \multirow[t]{2}{*}{ Syria } & 1990 & $14.74(12.85-16.83)$ & $39.01(33.45-46.23)$ & $3.68(3.02-4.49)$ & 170.1(138.79-210.71) \\
\hline & 2017 & $17.68(14.75-21.21)$ & $43.79(36.94-52.54)$ & $3.08(2.41-3.87)$ & $138.62(107.95-175.45)$ \\
\hline \multirow[t]{2}{*}{ Tunisia } & 1990 & $18.63(16.38-21.19)$ & $49.12(41.99-58.93)$ & $3.08(2.68-3.82)$ & $135.47(115.13-172.38)$ \\
\hline & 2017 & $21.39(17.89-25.5)$ & $52.14(43.91-63.05)$ & $3.11(2.39-3.93)$ & $133.02(100.73-171.74)$ \\
\hline \multirow[t]{2}{*}{ Turkey } & 1990 & $22.62(19.96-25.69)$ & $60.43(51.31-72.57)$ & $4.18(3.51-5.21)$ & $183.74(151.23-235.92)$ \\
\hline & 2017 & $23.69(19.97-27.96)$ & $58.01(48.35-70.6)$ & $3.31(2.86-3.79)$ & $163.68(141.12-187.58)$ \\
\hline \multirow[t]{2}{*}{ United Arab Emirates } & 1990 & $26.46(23.24-30.08)$ & $68.46(57.97-80.87)$ & $4.32(3.19-5.53)$ & $193.13(143.6-247.16)$ \\
\hline & 2017 & $29.01(24.66-34.2)$ & $71.08(59.44-85)$ & $5.07(3.61-6.48)$ & $221.71(163.85-282.93)$ \\
\hline \multirow[t]{2}{*}{ Yemen } & 1990 & $18.72(16.19-21.54)$ & $51.06(43.48-61.46)$ & $6.64(2.89-10.39)$ & $329.07(128.4-516.27)$ \\
\hline & 2017 & 17.91(15.22-20.85) & $47.05(40.17-56.23)$ & $6.01(4.44-8.21)$ & $287.89(216.04-390.5)$ \\
\hline \multirow[t]{2}{*}{ Global } & 1990 & $59.85(52.89-67.36)$ & $127.9(106.34-151.27)$ & $15.43(13.95-16.24)$ & $686.94(620.51-723.18)$ \\
\hline & 2017 & $50.09(42.45-58.88)$ & $105.47(87.72-124.09)$ & $9.98(9.35-10.3)$ & $428.97(401.57-443.48)$ \\
\hline \multirow[t]{2}{*}{ MENA } & 1990 & $22.82(20.04-25.94)$ & $58.63(49.59-70.09)$ & $5.71(4.91-6.65)$ & $271.31(232.38-318.82)$ \\
\hline & 2017 & $22.13(18.69-26)$ & $55.18(46.29-66.56)$ & $4.72(4.27-5.15)$ & $224.34(203.68-247.24)$ \\
\hline
\end{tabular}

resulting from other types of trauma, it includes lower rate of deaths. ${ }^{11}$

A complex network of factors including risk factors and protective factors in the individual, family and social level provide the context for suicide attempt. ${ }^{14-17}$ Contrary to Asian countries, there is a strong link between mental illness and suicide in the western countries. ${ }^{18}$ Given high focus on suicide prevention at the international and country level, statistical and trend data on suicide deaths including analysis based on region, country, age and gender are necessary for suicide prevention measures. However, because suicide attempt is considered a social stigma and is illegal in some countries, so its reporting is not complete and correct. This leads to incorrect classification and alteration of data. ${ }^{19,20}$ Regarding the study importance, on one hand, as countries have focused on preventing suicide, so identifying its different epidemiological aspects including prevalence in terms of age, sex, country and its trend is crucial for policy-making measures. On the other hand, these types of studies provide an opportunity to compare countries that finally describe the pattern of suicide. The aim of this study is to compare the burden of suicide in the Middle East and North Africa (MENA) countries to pave the way for correct policy making and reduce suicide attempt and mortality.

\section{Materials and methods}

The study population includes MENA region, which itself includes 21 countries in the Middle East and North Africa id est. Afghanistan, Algeria, Bahrain, Egypt, Iran, Iraq, Jordan, Kuwait, Lebanon, Libya, Morocco, Palestine, Oman, Qatar, Saudi Arabia, Sudan, Tunisia, Turkey, United Arab Emirates, Yemen. These countries were compared to the world in terms of age and gender according to the suicide risk factors.

The data of Global Burden of Diseases (GBD) 2017 was used in this study to present estimates of deaths due to 264 causes in terms of location, age and sex for 195 countries and regions. GBD considers suicide as death due to poisoning or intentional self-harm in accordance with the ninth and tenth editions of international classification of diseases (ICD- 10 codes X60- X64.9, X66- X84.9, Y87.0 and ICD-9 codes E950- E959). Information on the causes of death coded as suicide were collected from vital information registering systems and verbal autopsy reports. The vital information registering system collects information related to birth and death in the population, and using this data for analysis provides the most accurate cause of death at any time. Verbal autopsy is a method for mortality classification in places without a vital information registering system. This method utilizes from the educated 
interviewers for collecting information about the symptoms, signs and sociological data of the deceased to deduce the cause of death.

The Global Burden of Disease Study 2016 determined causes and reasons of death data coded as suicide using verbal autopsy reports (VAR) and vital registration systems (VRS). GBD study using VAR and VRS reach the highest quality of data. GBD 2016 considered variation in data quality through a series of ways, data standardization and distribution of inappropriate garbage codes that are impossible causes of death, or unspecific underlying causes of death, that are entered as the underlying causes of death on death certificates. ${ }^{6,21}$

The rates are standardized in GBD according to the total world population. In this study, the indicators of the number of disabilityadjusted life years (DALYs) which is calculated by summing years lived with disability (YLDs) and years of life lost (YLLs) ${ }^{22}$ and also age standardized incidence rate, age standardized prevalence rate, age standardized death rate in 100,000 people are reported. ${ }^{23,24}$ The analyses were performed in Microsoft Office Excel 2016.

\section{Results}

Regarding age standardized incidence rate of suicide in both sexes, the countries of Qatar 38.78 (34.63-43.38), Iran 30.86 (25.66-36.89), and Bahrain was 30.04 (26.66-33.95) in 100,000 had the highest, respectively, and Syria 14.74 (12.58-16.83), Saudi Arabia 15.36 (13.16-17.83), and Afghanistan 16.4 (14.56-18.57) in 100,000 had the lowest, respectively, among 21 countries in the Middle East and North Africa (MENA) in 1990. However, the countries of Qatar 31.09 (26.09-36.43), Libya 30.65 (26.24-35.84), and United Arab Emirates 29.01 (24.66-34.2) in 100,000 people had the highest age standardized incidence rate in 2017 , respectively.

The global suicide incidence and prevalence rate in terms of ASR have decreased from 1990 to 2017. This trend is also present in the MENA region countries. So that, the incidence and prevalence rate of suicide in terms of ASR in MENA countries in comparison with the mean global rate is lower. In general, the incidence, prevalence, death, and DALY of suicide in all MENA region countries are lower than the global average (Table 1 ).

The highest percentage of total DALY suicides attributed to alcohol and drug use risk factors are related to the United Arab Emirates and Afghanistan among the region countries from 1990 to 2017, respectively. Among these countries, Iran is the only country that has not had the suicide DALY rate attributed to alcohol consumption risk factor (Fig. 1).

DALY rate in the MENA region countries was lower than the global average in terms of ASR in 2017. This rate in Morocco among women and in Libya in men were higher than global average in terms of population ratio in the same year.

Men in Libya, Afghanistan and Yemen have the highest DALY rates according to ASR in the region, respectively. Also, among women in the region, Moroccan women had the highest rate and women in Libya, Afghanistan and Yemen had the same DALY rates according to ASR (Fig. 2).

The age trend of suicide incidence rate in 2017 in the MENA region is low compared to the global average. Suicide incidence rate in the world have an increasing trend until the age group of 20-24 years and then a decreasing trend. This trend has an increasing trend again in 65 years old and older. This trend is also observed in the countries of MENA region. Changes in the incidence suicide rate in Jordan in the age group of 85 years and older are clearly higher than the global average (Fig. 3).

\section{Discussion}

Suicide still continues to be a major preventable cause of death worldwide. So that, it has led to 9.98 deaths per 100,000 deaths in terms of ASR in $2017,{ }^{2}$ as well as it has placed among the 10 major causes of death in the Eastern Europe, Central Europe, Western Europe, Central Asia, Australia, South America, Latin America, and North America as high-income countries, and also it is also the leading cause of death all over the world. ${ }^{25}$

The incidence and prevalence rate of suicide have decreased from 1990 to 2017 in the world and in the MENA regions. This decreasing trend in MENA region have been lower than the world average. Also, there have been a decreasing trend in death rate and DALY caused by suicide. It requires further studies to indicate that decrease in death rate has been due to suicide preventive activities or improvement in population health. However, this reduction in age standardized death rate have not been universal. ${ }^{6}$ The countries of Qatar, Iran and Bahrain had the highest, and Syria, Saudi Arabia and Afghanistan had the lowest age standardized suicide incidence rates among the MENA countries in 1990, respectively. In 2017, Qatar continued to have the highest incidence rate, and Iran and Bahrain replaced with Libya and the United Arab Emirates. $75.5 \%$ of suicides cases occur in low- and middle-income countries (LMICs) that is in accordance with the available evidences regarding positive association between suicide and social and economic variables such as poverty, financial crisis, debt, and unemployment. ${ }^{26,27}$ Low or lack of studies in these areas may be an indicator of resource constraints and to some extent social stigma and criminalization of suicidal behavior. ${ }^{28}$

The use of pesticides poisons as the most common means of suicide in China from 2006 to 2013 has reduced from 55\% to 49\%. However, there is doubts if decrease in access to these poisons or reducing the lethality of them or another reason have caused this reduction. ${ }^{29}$ In the MENA region countries, from 1990 to 2017, the highest percentage of total DALY attributed to the alcohol and drug use risk factors was related to the United Arab Emirates and Afghanistan. The DALY rate attributed to alcohol risk factor was not seen in Iran. Suicide rates have increased in the United States than the past two decades, and with the outbreak of COVID-19 disease, the suicide rates have increased than relative welfare times due to stress and economic recession. On the other hand, the weekly attendance at religious ceremonies in the church has been concurrent with 5 times reductions in the number of suicides rates compared to those who did not attend these ceremonies. So, with the closure of religious and social centers and increase in social isolation leads to increase suicide rates. Generally, these patterns involve the complex interaction of specific factors in regions and countries, including sociological, cultural and religious factors, levels of economic development, unemployment, economic events, ${ }^{16,17}$ distribution of risk factors such as confrontation with violence, alcohol and drugs use, access options to suicide devices, patterns of mental illness and also specific cultural relationship with suicide. ${ }^{30,31}$ According to a previous study, men at all age groups except 15-19 years old have higher suicide rate than women. However, this gap was almost equal between 1990 and 2016.

The age trend of suicide incidence rate in 2017 in the MENA region is lower compared to the global average but this rate obviously exceeded the global average in Jordan in the age group of 85 years and older. Urbanization level, the proportion of literate population and differences in literacy rates between men and women have been considered as reasons for the change in mortality at the Indian states level. ${ }^{32-34}$ In 2016, high suicide mortality was observed among adolescent girls in India that has surpassed maternal mortality rate as the leading cause of death in the world. ${ }^{35,36}$ Several forms of gender differences and discriminations including early marriage and high risk of depression in women can be the main reasons. ${ }^{36,37}$

\section{Conclusion}

Despite advances in mortality reduction due to suicide in recent decades, it is still an important preventable factor in the global burden of diseases in all of the world. Improvement in social, cultural, and economic factors and performing effective measures to prevent suicide 


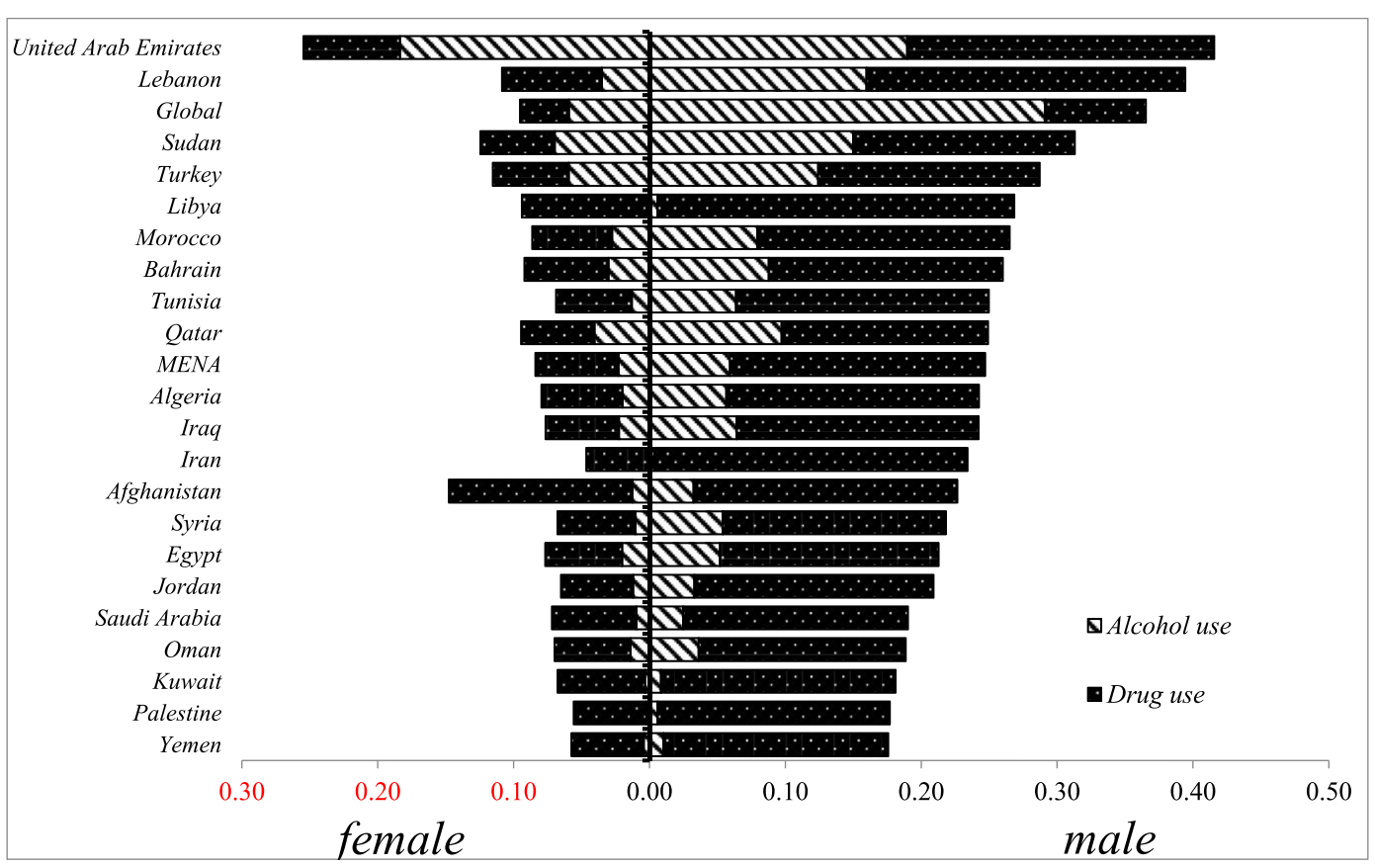

Fig. 1. The percentage of total suicide DALY according to ASR in both sexes attributed to risk factors alcohol and drug use.

in low- and middle-income countries, conducting more studies and precise registering of suicide in areas where suicide is a social stigma and crime can provide the background for suicide prevention and control. This issue claims a national and regional preventive strategy globally to address this public health concern. The countries should identify the most important suicide causes and design a comprehensive strategic package to educate the public and prevent suicide attempts.

\section{Author contributions}

Conceptualization, P.B. and Y.Y.; methodology, M.M.; software, M.M.; validation, P.B., Y.Y. and Z.Z.; investigation, M.B.; data curation,
U.R.; writing—original draft preparation, S.A., MA., M.M, M.B., and P.B.; writing-review and editing, S.A., MA, and U.R; supervision, M.B.; project administration, M.B. All authors have read and agreed to the published version of the manuscript.

\section{Funding}

This study was funded by Deputy of Research \& Technology of Kermanshah University of Medical Sciences, Kermanshah, Iran (Ethical Code Number: ir. kums.irc.1399.214).

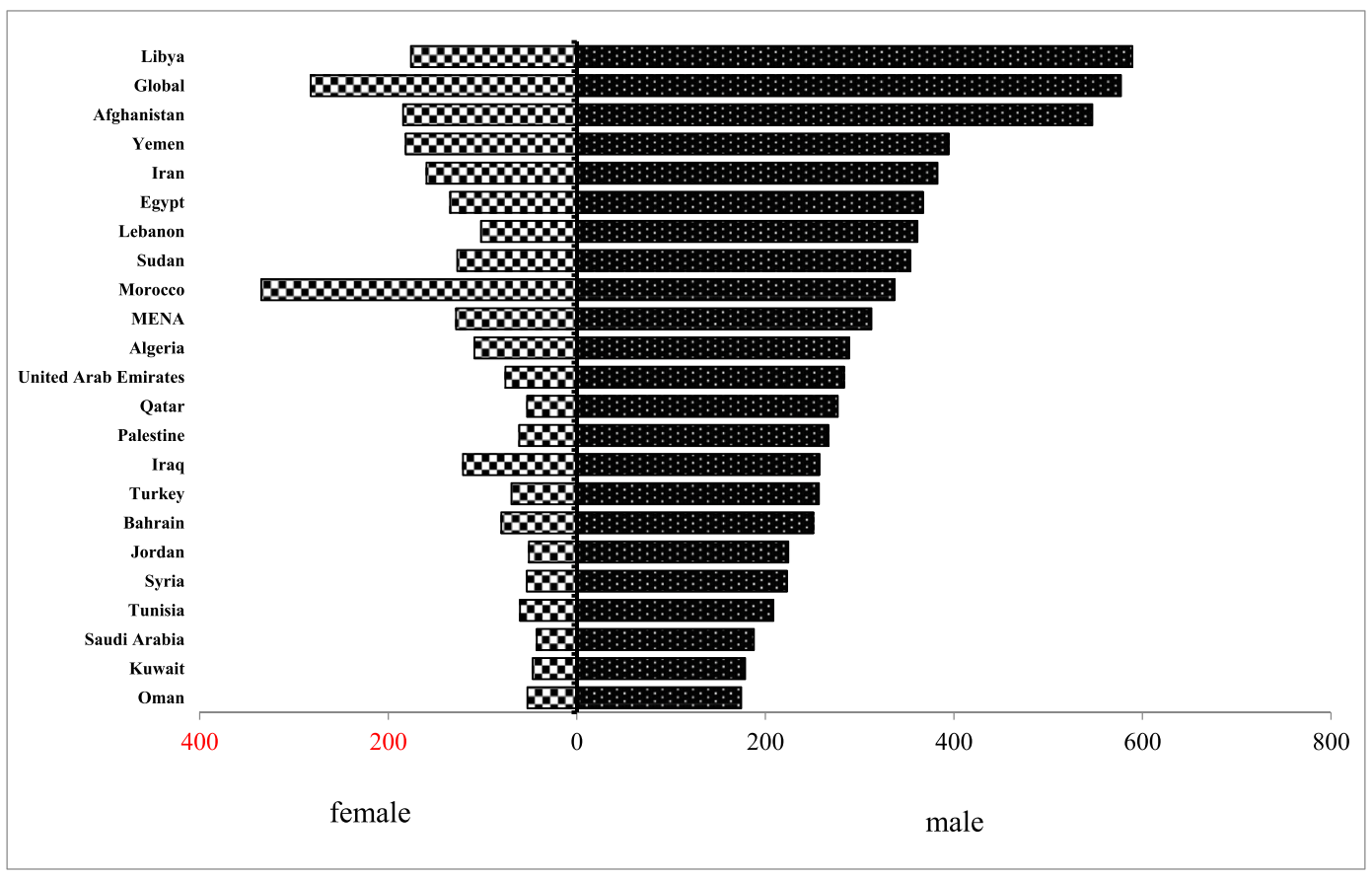

Fig. 2. Comparing suicide DALY rate in terms of ASR between two sexes in 2017. 


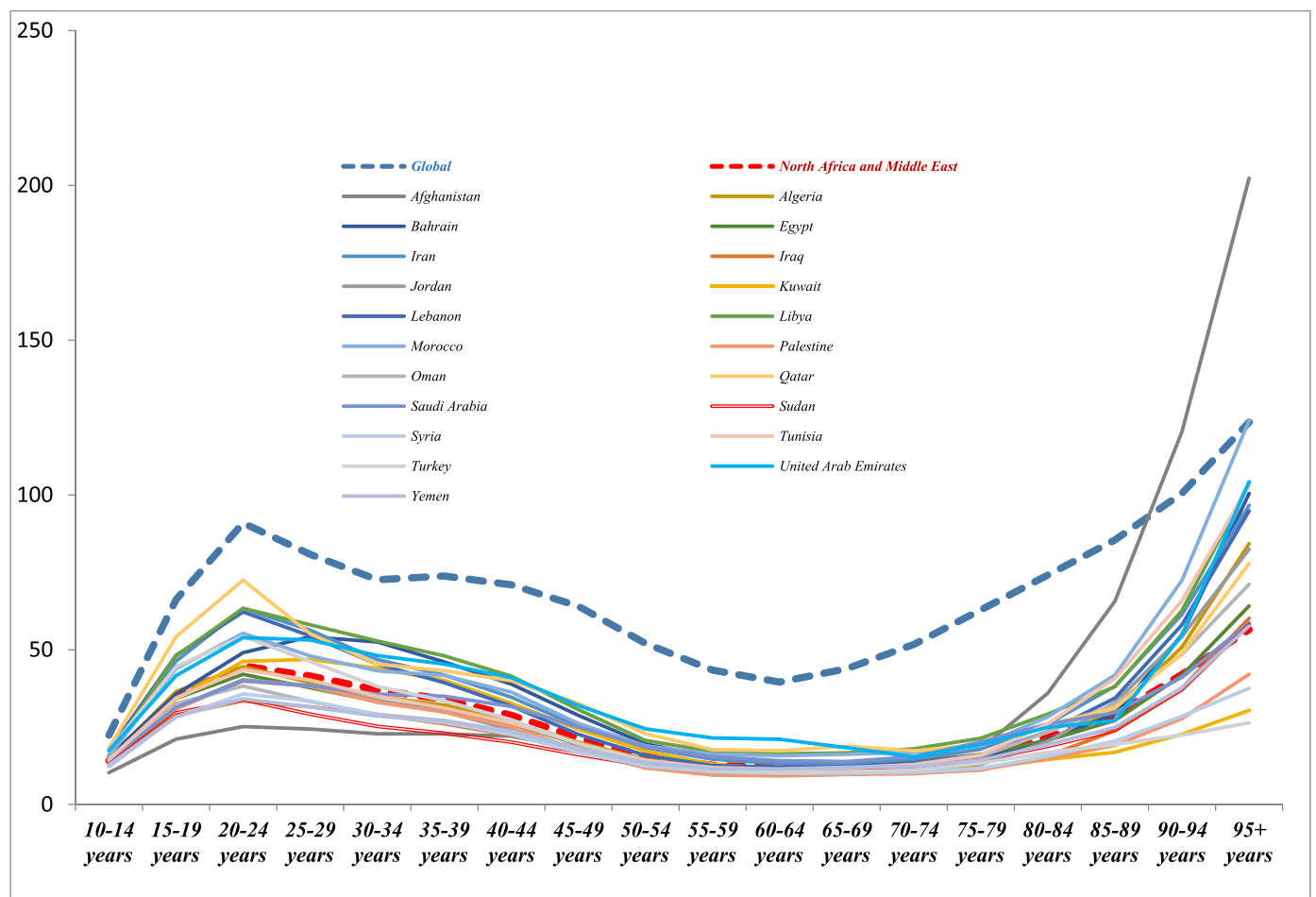

Fig. 3. The age trend of self-harm incidence rate in both sexes in the world and MENA countries in 2017.

\section{Declaration of competing interest}

The authors declare that they have no competing interests.

\section{Acknowledgments}

The authors would like to thanks health deputy and research deputy of Kermanshah University of Medical Sciences who provided the background to perform this study

\section{References}

1. Saxena S, Funk M, Chisholm D. Comprehensive mental health action plan 2013-2020. EMHJ-Eastern Mediterranean Health Journal. 2015;21(7):461-463.

2. Stone DM, Holland KM, Bartholow BN, Crosby AE, Davis SP, Wilkins N. Preventing Suicide: A Technical Package of Policies, Programs, and Practice. National Center for Injury Prevention and Control. Centers for Disease Control and Prevention; 2017.

3. Suicide rates per 100,000 by country, year and sex. Geneva: WHO. World Health Organization; 2011.

4. Gururaj G, Ahsan N, Isaac MK, Latief MA, Abeyasinghe R, Tantipiwatanaskul P. Suicide prevention: emerging from darkness. WHO Regional Office for South-East Asia; 2001:70.

5. Värnik P. Suicide in the world. Int J Environ Res Publ Health. 2012;9(3):760-771.

6. Naghavi M. Global, Regional, and National Burden of Suicide Mortality 1990 to 2016 : Systematic Analysis for the Global Burden of Disease Study. bmj; 2019:364.

7. Suicide Rates Rising across the US. Atlanta: Centers for Disease Control and Prevention, 2018.

8. Chang B, Gitlin D, Patel R. The depressed patient and suicidal patient in the emergency department: evidence-based management and treatment strategies. Emerg Med Pract. 2011;13(9):1-23.

9. Krug E. World Report on Violence and Health. World Health Organization; 2002.

10. Stern TA, Rosenbaum JF, Fava M, Biederman J, Rauch SL, et al. Massachusetts General Hospital Comprehensive Clinical Psychiatry. Elsevier Health Sci; 2008.

11. Pitman A, Krysinska K, Osborn D, King M. Suicide in young men. Lancet. 2012;379(9834):2383-2392

12. Yip PS, Caine E, Yousuf S, Chang SS, Wu KC, Chen YY. Means restriction for suicide prevention. Lancet. 2012;379(9834):2393-2399.

13. Summary tables of mortality estimates by cause, age and sex, globally and by region, 2000-2015. World Health Organization; 2018.

14. Darvishi N, Farhadi M, Haghtalab T, Poorolajal J. Alcohol-related risk of suicidal ideation, suicide attempt, and completed suicide: a meta-analysis. PLOS ONE. 2015;10(5):e0126870.

15. Devries K, Watts C, Yoshihama M, et al. Violence against women is strongly associated with suicide attempts: evidence from the WHO multi-country study on women's health and domestic violence against women. Soc Sci Med. 2011;73(1):79-86.
16. Oyesanya M, Lopez-Morinigo J, Dutta R. Systematic review of suicide in economic reces sion. World J Psychiatr. 2015;5(2):243

17. Rehkopf DH, Buka SL. The association between suicide and the socio-economic characteristics of geographical areas: a systematic review. Psychol Med. 2006;36(2):145-157.

18. Arsenault-Lapierre G, Kim C, Turecki G. Psychiatric diagnoses in 3275 suicides: a metaanalysis. BMC Psychiatr. 2004;4(1):37.

19. Kapusta ND, Tran US, Rockett IR, et al. Declining autopsy rates and suicide misclassification: a cross-national analysis of 35 countries. Arch Gen Psychiatr. 2011;68(10):1050-1057

20. Preventing Suicide: A Global Imperative. World Health Organization; 2014.

21. Moraga P. Global, regional, and national age-sex specific mortality for 264 causes of death, 1980-2016: a systematic analysis for the Global Burden of Disease Study 2016. Lancet. 2017;390(10100):1151-1210.

22. Haagsma JA, Graetz N, Bolliger I, et al. The global burden of injury: incidence, mortality, disability-adjusted life years and time trends from the Global Burden of Disease study 2013. Inj Prev. 2016;22(1):3-18.

23. Ahmad OB, Boschi-Pinto C, Lopez AD, Murray CJ, Lozano R, Inoue M. Age standardization of rates: a new WHO standard. 10th Geneva: World Health Organization; 2001.

24. Porta M. A Dictionary of Epidemiology. Oxford university press; 2014.

25. Naghavi M, Abajobir AA, Abbafati C, et al. Global, regional, and national age-sex specific mortality for 264 causes of death, 1980-2016: a systematic analysis for the Global Burden of Disease Study 2016. Lancet. 2017;390(10100):1151-1210.

26. Hawton K, Sutton L, Haw C, Sinclair J, Deeks JJ, et al. Schizophrenia and suicide: systematic review of risk factors. Br J Psychiatr. 2005;187(1):9-20.

27. Krysinska K, Lester D. Post-traumatic stress disorder and suicide risk: a systematic review. Arch Suicide Res. 2010;14(1):1-23.

28. Bantjes J, Iemmi V, Coast E, et al. Poverty and suicide research in low-and middle-income countries: systematic mapping of literature published in English and a proposed research agenda. Global Mental Health. 2016;3.

29. Page A, Liu S, Gunnell D, et al. Suicide by pesticide poisoning remains a priority for suicide prevention in China: analysis of national mortality trends 2006-2013. J Affect Disord. 2017;208:418-423.

30. Nock MK, Hwang I, Sampson N, et al. Cross-national analysis of the associations among mental disorders and suicidal behavior: findings from the WHO World Mental Health Surveys. PLoS Med. 2009;6(8):e1000123.

31. Phillips MR. Rethinking the Role of Mental Illness in Suicide. Am Psychiatric Assoc; 2010.

32. Arya V, Page A, River J, Armstrong G, Mayer P. Trends and socio-economic determinants of suicide in India: 2001-2013. Soc Psychiatr Psychiatr Epidemiol. 2018;53(3):269-278.

33. Mayer P. Suicide and Society in India. Routledge; 2010.

34. Patel V, Ramasundarahettige C, Vijayakumar L, et al. Suicide mortality in India: a nationally representative survey. The lancet. 2012;379(9834):2343-2351.

35. Petroni S, Patel V, Patton G. Why is suicide the leading killer of older adolescent girls? Lancet. 2015;386(10008):2031-2032.

36. Health for the World's Adolescents: A Second Chance in the Second Decade: Summary. World Health Organization; 2014

37. Patel V. Reducing the burden of depression in youth: what are the implications of neuroscience and genetics on policies and programs? J Adolesc Health. 2013;52(2):S36-S38. 